Original Research Paper

\title{
Cultural Intelligence: Key Benefits to Individuals, Teams and Organizations
}

\author{
Ana Azevedo \\ Faculty of Business, Athabasca University, Canada
}

Article history

Received: 16-10-2018

Revised: $18-11-2018$

Accepted: 12-12-2018

Email: Ana.Azevedo@fb.athabascau.ca

\begin{abstract}
This paper provides an overview of the empirical research on cultural intelligence, with a special focus on discussing key practical benefits to individuals, teams and organizations. The importance of cultural intelligence training is also highlighted.
\end{abstract}

Keywords: Cultural Intelligence, Benefits, Training

\section{Introduction}

Cultural intelligence (CQ) has been defined as an individual capability to effectively function in culturally-diverse situations (Ang and Van Dyne, 2015; Earley and Ang, 2003). This overall capability or competence is composed of four inter-related capabilities: CQ drive or motivational CQ (i.e., the ability to direct and sustain energy, as well as the confidence to adapt to cross-cultural situations), CQ knowledge or cognitive CQ (i.e., the knowledge and understanding regarding cultures, including their similarities and differences), CQ strategy or metacognitive CQ (i.e., the ability to plan, remain aware and monitor thought processes, in order to understand intercultural situations) and CQ action or behavioral CQ (i.e., the ability to modify verbal and non-verbal behaviors in intercultural settings) (Ang et al., 2015; Livermore, 2015; Van Dyne et al., 2012). These capabilities meaningfully complement each other to support behavioral flexibility within cross-cultural settings. CQ applies to different cultures as well as subcultures, so it helps individuals and organizations to improve work performance in highly diverse and/or global organizational settings (Livermore, 2016; Malek and Budhwar, 2013; Rockstuhl et al., 2011).

CQ is a malleable competence that can be increased through training and coaching, combined with selfassessments and individual development plans (in a way that augments the effects of each of these activities). In addition, after taking part in a CQ training program, individuals and teams are in a better position to further their own intercultural competence via on-the-job experiences (e.g., working in a multicultural team, undertaking an international assignment, engaging in international negotiations to open up new markets or expand sales to key international customers) (Imai and Gelfand, 2010; Livermore, 2011; Raver and Van Dyne, 2017).

Comprehensive reviews of cultural intelligence research have been provided in recent years (Ang et al., 2011; Leung et al., 2014; Ng et al., 2012; Fang et al., 2018; Ott and Michailova, 2018). The goal of this paper is to review and discuss key practical benefits of cultural intelligence to individuals, teams and organizations. In addition, the importance of providing cross-cultural training for organizational leaders and employees is underscored, given the need to adequately prepare them to fully leverage these benefits (Bartel-Radic and Giannelloni, 2017; Barrera, 2010; Bird et al., 2010).

\section{Cultural Intelligence: Key Benefits}

An extensive amount of empirical research has been carried out since the concept of cultural intelligence was originally proposed by Earley and Ang (2003). One of the key issues that has been studied during the past fifteen years is the impact of cultural intelligence on specific outcomes that are relevant for the workplace (Ang and Van Dyne, 2015; Ott and Michailova, 2018). Benefits associated with an individual's high CQ include the ability to effectively perform in situations that are culturally-diverse (e.g., working on a project with culturally-diverse colleagues) or that have a global component (e.g., working with suppliers or customers in international markets) (Fang et al., 2018). This ability to perform effectively also applies to work contexts involving other types of diversity (e.g., intergenerational or gender diversity) (Groves and Feyerherm, 2011; Livermore, 2015).

From existing research, it is possible to conclude that individuals and teams with high CQ will experience a number of specific benefits that have been described as psychological outcomes (e.g., effective intercultural 
adjustment; improved cultural judgment; greater interpersonal trust), behavioral outcomes (e.g., improved decision-making; higher levels of idea-sharing, information-sharing and creative collaboration among teams) and performance outcomes (e.g., effective intercultural negotiations; increased work performance) (Gelfand et al., 2015; Leung et al., 2014). Aside from the positive impact of these individual and teamrelated outcomes, organizations can derive additional benefits such as an increase in profitability and cost savings (due to, for example, the adoption of more innovative methods); greater expansion into international markets; better service that is tailored to the specific needs of different groups of customers and more effective Human Resources practices to attract and manage talent within the context of an increasingly diverse and global workforce (Ang et al., 2011; Livermore, 2015; 2016). In the following sections, this paper will review and discuss key CQ benefits for individuals, teams and organizations.

\section{Increased Intercultural Adjustment}

Individuals with high CQ show better emotional and psychological adjustment to situations involving different or unfamiliar cultures (and subcultures). This helps individuals experience less burnout and have higher resilience (i.e., the ability to bounce back and recover in stressful situations) when working across cultures/subcultures. Culturally intelligent individuals show greater perseverance in tough situations, as well as higher levels of stamina and productivity. In addition, individuals with high $\mathrm{CQ}$ can adjust more easily to uncertain, complex and shifting work demands which are typically encountered in intercultural situations (e.g., working in multi-cultural team) (Guomundsdottir, 2015; Lin et al., 2012; Malek and Budhwar, 2013; Moon et al., 2012; Tay et al., 2015; Tuleja, 2017).

\section{Improved Cultural Judgment and Decision-Making}

Culturally intelligent individuals are better equipped to understand and evaluate situations that include multiple perspectives and to make high-quality decisions within intercultural contexts. Cultural intelligence helps individuals and teams to cooperate in finding effective/mutually acceptable solutions that address different priorities and perspectives (Ang et al., 2007; Van Dyne et al., 2010; Ng et al., 2009).

\section{Greater Effectiveness in Intercultural Negotiations}

Individuals and teams engaged in international negotiations (e.g., international contract negotiations) often face complex and lengthy discussions in order to reach an agreement. Whether these discussions involve diverse company colleagues, clients or suppliers, individuals and teams with high CQ show more patience and greater ability to persist and collaborate across cultures and borders, in order to negotiate and develop favorable, 'win-win' agreements. These positive results come from their ability to better understand and incorporate diverse perspectives into the negotiation process (Imai and Gelfand, 2010; Chua et al., 2012; Groves et al., 2015).

\section{Higher Levels of Trust, Idea-sharing, Information- Sharing and Creative Collaboration}

In spite of the great potential of diversity to enhance creativity and innovation for individuals and organizations, the evidence suggests that heterogeneous multicultural teams tend to underperform homogeneous ones, unless team members have a good amount of intercultural competence. Individuals and teams with high CQ are more capable of trusting each other, which leads to higher levels of information-sharing and ideasharing. Consequently, culturally intelligent individuals and teams engage in more creative collaboration and come up with more innovative solutions. It is noteworthy that CQ helps to reduce the perceived interpersonal risks of speaking up among culturallydiverse teams of work colleagues and/or partners. Culturally intelligent individuals and teams are more likely to experience greater psychological safety, due to the positive association of CQ with higher trust (teams with high CQ also show faster acceptance and integration of team members, as well as greater team cohesion). The significant association between cultural intelligence and trust can be explained by CQ's role in attenuating social categorization processes that negatively impact interpersonal interactions among culturally-diverse individuals and teams (e.g., individuals categorizing others as belonging to either ingroups or outgroups). (Chen and Lin, 2013; Chua et al., 2012; Flaherty, 2015; Janssens and Brett, 2006; Livermore, 2016; Mor et al., 2013).

\section{Increased Work Performance}

Individuals with high CQ perform better when their leader or subordinate comes from a different cultural background, as compared to individuals with low CQ. Similarly, multicultural teams with high CQ outperform teams with low CQ. There are a number of studies supporting this positive relationship between cultural intelligence and work performance within a variety of intercultural contexts. For example, high CQ positively impacts task performance in culturally-diverse settings, adaptive performance (i.e., proficiency in changing one's behavior to fit the demands of the environment or the specific situation), global leadership effectiveness, sales performance in international or cross-cultural contexts and export performance (Groves and Feyerherm, 2011; Oolders et al., 2015; Presbitero, 2016; Wang 2016). 


\section{Conclusion}

Organizations that invest in cultural intelligence training can increase work performance of culturallydiverse individuals and teams. CQ training can be of special value to organizations that want to improve the collaboration and work effectiveness of global teams (e.g., geographically dispersed teams), to strengthen specific diversity and inclusion initiatives (e.g., accelerate leadership development among women and minorities) and to further support learning and development goals for different groups of employees. Considering the growing adaptive challenges associated with the so-called VUCA (i.e., volatility, uncertainty, complexity and ambiguity) world, cultural intelligence training can help promote the development of key 'future skills' in individuals and teams, such as adaptability/flexibility, teamwork and collaboration, resilience and creativity and innovation. (Pearse, 2017; Tuleja, 2017; Van Dyne et al., 2017; Morris et al., 2014; WEF, 2018).

\section{Acknowledgment}

This literature review is part of a comprehensive pilot study which was designed and implemented between the July 2016 and December 2017. The author gratefully acknowledges the support of Athabasca University during her research and study leave.

\section{Ethics}

This article is original and only contains unpublished material.

\section{References}

Ang, S., T. Rockstuhl and M.L. Tan, 2015. Cultural intelligence and competencies. Int. Encycl. Soc. Behav. Sci., 2: 433-439.

DOI: 10.1016/B978-0-08-097086-8.25050-2

Ang, S. and Van Dyne, L. 2015. Conceptualization of Cultural Intelligence: Definition, Distinctiveness and Nomological Network. In: Handbook of Cultural intelligence: Theory, Measurement and Applications, Ang, S. and L. Van Dyne (Eds.), Routledge, New York, ISBN-13: 9780765622624, pp: 21-33.

Ang, S., L. Van Dyne, C. Koh, K.Y. Ng and K.J. Templer et al., 2007. Cultural intelligence: Its measurement and effects on cultural judgment and decision making, cultural adaptation and task performance. Manage. Organiz. Rev., 3: 335-371. DOI: $10.1111 / \mathrm{j} .1740-8784.2007 .00082 . \mathrm{x}$

Ang, S., L. Van Dyne and M.L. Tan, 2011. Cultural Intelligence. In: Cambridge Handbook on Intelligence, Sternberg, R.J. and S.B. Kaufman (Eds.), Cambridge Press, New York, pp: 582-602.
Barrera, J.C., 2010. An examination of cross cultural competence in international business: The case of the subsidiaries. Int. Bus. Econom. Res. J., 9: 41-54. DOI: 10.19030/iber.v9i1.507

Bartel-Radic, A. and J.L. Giannelloni, 2017. A renewed perspective on the measurement of cross-cultural competence: An approach through personality traits and cross-cultural knowledge. Eur. Manage. J., 35: 632-644. DOI: 10.1016/j.emj.2017.02.003

Bird, A., M. Mendenhall, M.J. Stevens and G. Oddou, 2010. Defining the content domain of intercultural competence for global leaders. J. Managerial Psychol., 25: 810-828.

DOI: $10.1108 / 02683941011089107$

Chen, M.L. and C.P. Lin, 2013. Assessing the effects of cultural intelligence on team knowledge sharing from a socio-cognitive perspective. Human Resource Manage., 52: 675-695. DOI: 10.1002/hrm.21558

Chua, R.Y.J., M.W. Morris and S. Mor, 2012. Collaborating across cultures: Cultural metacognition and affect-based trust in creative collaboration. Organiz. Behav. Human Dec. Processes, 118: 116-131. DOI: $10.2139 /$ ssrn. 1861054

Earley, P.C. and S. Ang, 2003. Cultural Intelligence: Individual Interactions across Cultures. 1st Edn., Stanford University Press, California. ISBN-13: 9780804743129

Fang, F., V. Schei and M. Selart, 2018. Hype or hope? A new look at the research on cultural intelligence. Int. J. Intercultural Relat., 66: 148-171. DOI: $10.1016 /$ j.ijintrel.2018.04.002

Flaherty, J.E., 2015. The Effects of Cultural Intelligence on Team Member Acceptance and Integration in Multinational Teams. 2nd Edn., In: Handbook of Cultural intelligence: Theory, Measurement and Applications, Ang, S. and L. Van Dyne (Eds.), Routledge, New York, ISBN-13: 9780765622624 , pp: 192-205.

Gelfand, M.J., L. Imai and R. Fehr, 2015. Thinking Intelligently about Cultural Intelligence: The Road Ahead. In: Handbook of Cultural intelligence: Theory, Measurement and Applications, Ang, S. and L. Van Dyne (Eds.), Routledge, New York, ISBN: 9780765622624, pp: 375-387.

Groves, K.S. and A.E. Feyerherm, 2011. Leader cultural intelligence in context: Testing the moderating effects of team cultural diversity on leader and team performance. Group Organiz. Manage., 36: 535-566. DOI: $10.1177 / 1059601111415664$

Groves, K.S., A. Feyerherm and M. Gu, 2015. Examining cultural intelligence and cross-cultural negotiation effectiveness. J. Manage. Educ., 39: 209-243. DOI: $10.1177 / 1052562914543273$

Guomundsdottir, S., 2015. Nordic expatriates in the US: The relationship between cultural intelligence and adjustment. Int. J. Intercultural Relat., 47: 175-186. DOI: $10.1016 /$ j.ijintrel.2015.05.001 
Imai, L. and M.J. Gelfand, 2010. The culturally intelligent negotiator: The impact of cultural intelligence (CQ) on negotiation sequences and outcomes. Organiz. Behav. Human Dec. Processes, 112: 83-98. DOI: 10.1016/j.obhdp.2010.02.001

Janssens, M. and J.M. Brett, 2006. Cultural intelligence in global teams: A fusion model of collaboration. Group Organiz. Manage., 31: 124-153. DOI: $10.1177 / 1059601105275268$

Leung, K., S. Ang and M.L. Tan, 2014. Intercultural competence. Annual Rev. Organiz. Psychol. Organizat. Behav., 1: 489-519.

DOI: 10.1146/annurev-orgpsych-031413-091229

Lin, Y.C., A.S.Y. Chen and Y.C. Song, 2012. Does your intelligence help to survive in a foreign jungle? The effects of cultural intelligence and emotional intelligence on cross-cultural adjustment. Int. J. Intercultural Relat., 36: 541-552.

DOI: $10.1016 /$ j.ijintrel.2012.03.001

Livermore, D., 2011. The Cultural Intelligence Difference: Master the One Skill You Can't Do without in Today's Global Economy. 1st Edn., AMACOM, New York, ISBN-13: 9780814417065.

Livermore, D., 2015. Leading with Cultural Intelligence: The Real Secret to Success. 2nd Edn., AMACOM, New York, ISBN-13: 9780814449172.

Livermore, D., 2016. Driven by Difference: How Great Companies Fuel Innovation through Diversity. 1st Edn., AMACOM, New York, ISBN-13: 9780814436530.

Malek, M.A. and P. Budhwar, 2013. Cultural intelligence as a predictor of expatriate adjustment and performance in Malaysia. J. World Bus., 48: 222-231. DOI: 10.1016/j.jwb.2012.07.006

Moon, H.K., B.K. Choi and J.S. Jung, 2012. Previous international experience, cross-cultural training and expatriates' cross-cultural adjustment: Effects of cultural intelligence and goal orientation. Human Resource Dev. Quarterly, 23: 285-330. DOI: $10.1002 / \mathrm{hrdq} .21131$

Mor, S., M.W. Morris and J. Joh, 2013. Identifying and training adaptive cross-cultural management skills: The crucial role of cultural metacognition. Acad. Manage. Learn. Educ., 12: 453-475. DOI: 10.5465 /amle.2012.0202

Morris, M.W., K. Savani, S. Mor and J. Cho, 2014. When in Rome: Intercultural learning and implications for training. Res. Organizat. Behav., 34: 189-215. DOI: 10.1016/j.riob.2014.09.003

Ng, K.Y., L. Van Dyne and S. Ang, 2009. From experience to experiential learning: Cultural intelligence as a learning capability for global leader development. Acad. Manage. Learn. Educ., 8: 511-526. DOI: 10.5465/amle.2009.47785470
Ng, K.Y., L. Van Dyne and S. Ang, 2012. Cultural Intelligence: A Review, Reflections and Recommendations for future Research. In: Conducting Multinational Research Projects in Organizational Psychology, Ryan, A.M., F.T.L. Leong and F. Oswald (Eds.), American Psychological Association, Washington, DC, pp: 29-58.

Ott, D.L. and S. Michailova, 2018. Cultural intelligence: A review and new research avenues. Int. J. Manage. Rev., 20: 99-119. DOI: 10.1111/ijmr.12118

Oolders, T., O.S. Chernyshenko and S. Shark, S. 2015. Cultural Intelligence as a Mediator of Relationships Between Openness to Experience and Adaptive Performance. In: Handbook of Cultural intelligence: Theory, Measurement and Applications, Ang, S. and L. Van Dyne (Eds.), Routledge, New York, ISBN-13: 9780765622624, pp: 145-158.

Pearse, N.J., 2017. Change Management in a VUCA World. In: Visionary Leadership in a Turbulent World: Thriving in The New VUCA Context, Elkington, R., M. Van Der Steege, J. Glick-Smith and J.M. Breen (Eds.), Emerald Publishing Limited, Bingley, UK, ISBN-13: 9781787142435, pp: 195-226.

Presbitero, A., 2016. Cultural intelligence (CQ) in virtual, cross-cultural interactions: Generalizability of measure and links to personality dimensions and task performance. Int. J. Intercultural Relat., 50: 29-38. DOI: 10.1016/j.ijintrel.2015.11.001.

Raver, J.L. and L. Van Dyne, 2017. Developing Cultural Intelligence. In: The Cambridge Handbook of Workplace Training and Employee Development, Brown, K. (Ed.), Cambridge Handbooks in Psychology, Cambridge University Press, Cambridge, England, pp: 407-440.

Rockstuhl, T., S. Seiler, S. Ang, L. Van Dyne and H. Annen, 2011. Beyond general Intelligence (IQ) and emotional intelligence (EQ): The role of cultural intelligence (CQ) on cross-border leadership effectiveness in a globalized world. J. Soc. Issues, 67: 825-840.

Tay, C., M. Westman and A. Chia, 2015. Antecedents and Consequences of Cultural Intelligence among Short-term Business Travelers. In: Handbook of Cultural Intelligence: Theory, Measurement and Applications, Ang, S. and L. Van Dyne (Eds.), Routledge, New York, ISBN-13: 9780765622624 , pp: 126-144.

Tuleja, E.A., 2017. Cultural Intelligence in a VUCA World. In: Visionary Leadership in a Turbulent World: Thriving in The New VUCA Context, Elkington, R., M. Van Der Steege, J. Glick-Smith and J.M. Breen (Eds.), Emerald Publishing Limited, Bingley, UK, ISBN-13: 9781787142435 , pp: 195-226. 
Van Dyne, L., S. Ang and D. Livermore, 2010. Cultural Intelligence: A Pathway for Leading in a Rapidly Globalizing World. In: Leadership Across Differences: Casebook, Hannum, K.M., B. McFeeters and L. Booysen (Eds.), Pfeiffer, San Francisco, pp: 131-138.

Van Dyne, L., S. Ang, K.Y. Ng, T. Rockstuhl and M.L. Tan et al., 2012. Sub-dimensions of the four factor model of cultural intelligence: Expanding the conceptualization and measurement of cultural intelligence. Soc. Personality Psychol. Compass, 6: 295-313. DOI: 10.1111/j.1751-9004.2012.00429.x
Van Dyne, L., S. Ang and M.L. Tan, 2017. Cultural intelligence. Oxford University Press, Oxford, UK. DOI: $10.1093 /$ obo/9780199846740-0115

Wang, M., 2016. Effects of expatriates' cultural intelligence on cross-cultural adjustment and job performance. Revista Cercetare Interventie Sociala, 55: 231-243.

WEF, 2018. The future of jobs report 2018. Centre for the New Economy and Society, World Economic Forum, Geneva, Switzerland. 